\title{
Object-based assessment of burn severity in diseased forests using high-spatial and high-spectral resolution MASTER airborne imagery
}

\author{
Gang Chen ${ }^{\mathrm{a}, *}$, Margaret R. Metz ${ }^{\mathrm{b}, \mathrm{c}}$, David M. Rizzo ${ }^{\mathrm{b}}$, Whalen W. Dillon ${ }^{\mathrm{d}, \mathrm{e}}$, Ross K. Meentemeyer ${ }^{\mathrm{d}, \mathrm{e}}$ \\ ${ }^{a}$ Department of Geography and Earth Sciences, University of North Carolina at Charlotte, 9201 University City Blvd, Charlotte, NC 28223, USA \\ ${ }^{\mathrm{b}}$ Department of Plant Pathology, University of California, 1 Shields Ave, Davis, CA 95616, USA \\ ${ }^{\mathrm{c}}$ Department of Biology, Lewis \&' Clark College, 0615 S.W. Palatine Hill Road, MSC 53, Portland, OR 97219, USA \\ ${ }^{\mathrm{d}}$ Center for Geospatial Analytics, North Carolina State University, 3120 Jordan Hall, Raleigh, NC 27695, USA \\ ${ }^{\mathrm{e}}$ Department of Forestry E' Environmental Resources, North Carolina State University, 3120 Jordan Hall, Raleigh, NC 27695, USA
}

\section{A R T I C L E I N F O}

\section{Article history:}

Received 23 April 2014

Received in revised form 10 November 2014

Accepted 9 January 2015

Available online 6 February 2015

\section{Keywords:}

GEOBIA

Burn severity

Band reduction

Forest disease

Interacting disturbances

PCA (principal component analysis)

MNF (minimum noise fraction)

\begin{abstract}
A B S T R A C T
Forest ecosystems are subject to a variety of disturbances with increasing intensities and frequencies, which may permanently change the trajectories of forest recovery and disrupt the ecosystem services provided by trees. Fire and invasive species, especially exotic disease-causing pathogens and insects, are examples of disturbances that together could pose major threats to forest health. This study examines the impacts of fire and exotic disease (sudden oak death) on forests, with an emphasis on the assessment of post-fire burn severity in a forest where trees have experienced three stages of disease progression prefire: early-stage (trees retaining dried foliage and fine twigs), middle-stage (trees losing fine crown fuels), and late-stage (trees falling down). The research was conducted by applying Geographic Object-Based Image Analysis (GEOBIA) to MASTER airborne images that were acquired immediately following the fire for rapid assessment and contained both high-spatial $(4 \mathrm{~m}$ ) and high-spectral (50 bands) resolutions. Although GEOBIA has gradually become a standard tool for analyzing high-spatial resolution imagery, high-spectral resolution data (dozens to hundreds of bands) can dramatically reduce computation efficiency in the process of segmentation and object-based variable extraction, leading to complicated variable selection for succeeding modeling. Hence, we also assessed two widely used band reduction algorithms, PCA (principal component analysis) and MNF (minimum noise fraction), for the delineation of image objects and the subsequent performance of burn severity models using either PCA or MNF derived variables. To increase computation efficiency, only the top 5 PCA and MNF and top 10 PCA and MNF components were evaluated, which accounted for $10 \%$ and $20 \%$ of the total number of the original 50 spectral bands, respectively. Results show that if no band reduction was applied the models developed for the three stages of disease progression had relatively similar performance, where both spectral responses and texture contributed to burn assessments. However, the application of PCA and MNF introduced much greater variation among models across the three stages. For the early-stage disease progression, neither band reduction algorithms improved or retained the accuracy of burn severity modeling (except for the use of 10 MNF components). Compared to the no-band-reduction scenario, band reduction led to a greater level of overestimation of low-degree burns and underestimation of medium-degree burns, suggesting that the spectral variation removed by PCA and MNF was vital for distinguishing between the spectral reflectance from disease-induced dried crowns (still retaining high structural complexity) and fire ash. For the middle-stage, both algorithms improved the model $R^{2}$ values by $2-37 \%$, while the late-stage models had comparable or better performance to those using the original 50 spectral bands. This could be explained by the loss of tree crowns enabling better signal penetration, thus leading to reduced spectral variation from canopies. Hence, spectral bands containing a high degree of random noise were correctly removed by the band reduction algorithms. Compared to the middle-stage, the late-stage forest stands were covered by large piles of fallen trees and branches, resulting in higher variability of MASTER imagery. The ability of band reduction to improve the model performance for these late-stage forest stands was reduced, because the valuable spectral variation representing the actual late-stage forest status was partially removed by both algorithms as noise. Our results indicate that PCA and MNF are promising for balancing computation efficiency and the performance of burn severity models in forest stands subject to the middle and late stages of sudden oak death disease progression.
\end{abstract}

\footnotetext{
* Corresponding author. Tel.: +1 704687 5947; fax: +1 7046875966.

E-mail address: gang.chen@uncc.edu (G. Chen).
} 
Compared to PCA, MNF dramatically reduced image spectral variation, generating larger image objects with less complexity of object shapes. Whereas, PCA-based models delivered superior performance in most evaluated cases suggesting that some key spectral variability contributing to the accuracy of burn severity models in diseased forests may have been removed together with true spectral noise through MNF transformations.

Published by Elsevier B.V. on behalf of International Society for Photogrammetry and Remote Sensing, Inc.

(ISPRS).

\section{Introduction}

Forests are an integral part of many terrestrial ecosystems, providing a wide range of ecological, economic, social and cultural services. The structure and function of forests result from a dynamic process of tree recruitment, growth, and death, and the influence of a variety of disturbances (e.g., fires, storms, and diseases) (Asner, 2013). Major disturbance events could initially harm most of the ecosystem services delivered by trees. However, depending on the extent, severity and type of disturbance, some ecosystem services may be regained during forest succession, while the others may be permanently disrupted (Boyd et al., 2013). Wildfires and invasive species (especially exotic disease-causing pathogens and insects) are examples of the disturbances that may cause permanent and unexpected changes to forest landscapes and the associated services. The U.S. Forest Service currently lists them as two of the four major threats to the health of the nation's forests (U.S. Forest Service, 2014). Although neither disturbance is new, a growing number of studies have found that their intensities and frequencies have substantially increased over the past decade, as a result of global change (Bergot et al., 2004; Wulder et al., 2006; Kurz et al., 2008; Aukema et al., 2010; Olsson et al., 2012; Boyd et al., 2013). Fires of higher severity may also be more likely to occur in forests where invasive diseases or insects have caused high tree mortality (Jenkins et al., 2008; Harvey et al., 2013). Furthermore, the interaction of fire and insects or disease disturbances may alter forest ecosystems in unexpected ways (Metz et al., 2013), challenging our ability to predict the severity of burns across large infested landscapes.

Remote sensing has proven effective in large-area fire detection and burn severity mapping across a diversity of environments by linking the fire-induced physical changes in the land surface to variations in spectral reflectance from remotely sensed images (Hall et al., 1980; Milne, 1986; Jakubauskas et al., 1990; White et al., 1996; Hudak and Brockett, 2004; Lentile et al., 2006; Veraverbeke et al., 2012). Two types of approaches are typically used to model burn severity: statistical regression (deriving continuous burn severity values) or classification (retrieving discrete burn severity classes). Compared to field efforts required to directly measure the post-fire burn effects, remote sensing offers a dramatically less expensive alternative that is especially appropriate for managing large and topographically complex landscapes. However, accurate burn severity assessment may become a challenging task if exotic diseases or insects have caused extensive pre-fire tree mortality. Disease-related mortality can lead to a significant rise in shortwave infrared surface reflectance and a decrease in the near infrared reflectance, which is similar to the reflectance created by ash or charred remains after combustion of vegetation (Guyot et al., 1989; Roy and Landmann, 2005). Thus, pre-fire mortality may be confounded with burn severity in infested areas where low-severity fire also occurred. To understand the degree to which these factors may influence the accuracy of burn severity assessment, it is necessary to examine mapped burn severity across various stages of disease or insect progression; however, this has not been well investigated yet.
Recent developments in the sensor technologies used in remote sensing have made it possible to improve the accuracy of burn severity assessment using high-spatial and/or high-spectral resolution imagery. For example, Mitri and Gitas (2008) successfully mapped burn severity with an overall accuracy of $83 \%$ using $4 \mathrm{~m}$ IKONOS imagery, while Veraverbeke et al. (2012) found that the char fraction cover derived from 50-band MASTER data was strongly correlated with field-measured burn severity. High-spatial resolution imagery enables the evaluation of the degree of burn heterogeneity at the small patch level, which could aid in a better characterization of the complex effects from fire and disease/insect interactions (Turner et al., 1998; Lentile et al., 2006; Meentemeyer et al., 2012). High-spectral resolution imagery may further improve the analysis of such effects due to its increased sensitivity to the spectral variations from terrestrial features (Thenkabail et al., 2012). Since the early 2000s, Geographic Object-Based Image Analysis (GEOBIA) has been increasingly used to extract and analyze geographic objects from high-spatial resolution imagery (Blaschke et al., 2014). Unlike the prevailing per-pixel methods, GEOBIA applies segmentation-generated image objects (i.e., aggregates of pixels) to mimic the human perception of the real objects on the ground (Hay and Castilla, 2008). While promising results of applying GEOBIA have been reported in numerous studies from various fields (Blaschke et al., 2014), less consideration has been given to the application of data sets featuring both high-spatial and high-spectral resolutions. Compared to the typical multispectral data with less than ten spectral bands (e.g., IKONOS, SPOT, and QuickBird), images with a high-spectral resolution contain dozens to hundreds of spectral bands. An immediate consequence is that the computation efficiency in segmentation (a common process in GEOBIA) could be dramatically reduced. Furthermore, compared to the per-pixel feature extraction, a greater number of post-segmentation object-based features (also called feature bands) are often extracted in order to better define ground objects and the spatial interactions between neighboring objects, such as shape, size, and object-based texture or patterns (Hay et al., 1996; Kelly et al., 2008; Chen et al., 2011). Once all the spectral and feature bands are combined as inputs for subsequent modeling, selecting the optimal subset (from a pool of at least hundreds of objectbased bands) could pose major challenges (e.g., time-consuming and error-prone) to GEOBIA practitioners. Reducing the number of original spectral bands prior to GEOBIA processing is an intuitive solution to address this issue; however, it remains unclear how this procedure influences the precision in delineating objects (e.g., object size and shape) and the accuracy of burn severity modeling in disease-impacted forests.

Based on the above considerations, in this research we studied the 2008 Basin Complex Fire in the Big Sur, California ecoregion, which burned over 95,000 hectares of forest (USDA Forest Service, 2008) that was patchily infested by the exotic forest pathogen Phytophthora ramorum, the cause of sudden oak death (SOD; Rizzo et al., 2005). This non-native pathogen is estimated to have killed hundreds of thousands of host trees in the Big Sur forests since the mid-1990s (Meentemeyer et al., 2008). Interestingly, disease progression is not uniform across the landscape, resulting in forest 
stands experiencing varying stages of invasion and levels of disease-related mortality. This variability in disease progression and tree mortality has been linked to variation in field measurements of burn severity following the Basing Complex Fire (Metz et al., 2011, 2013). Our interest in improving post-fire rapid assessment of burn severity across large forested landscapes heterogeneously impacted by pests or pathogens led us to explore two research questions: (i) How do different stages of SOD progression affect the accuracy of forest burn severity modeled with images having both high-spatial and high-spectral resolutions? (ii) How does spectral band reduction influence the delineation of image objects and the accuracy of subsequent object-based burn severity models?

\section{Methods}

\subsection{Study area}

Our study site (centered at: $36^{\circ} 16^{\prime} \mathrm{N}, 121^{\circ} 44^{\prime} \mathrm{W}$ ) covers an area of 28,383 ha on the western flank of the Santa Lucia Mountains in the Big Sur ecoregion of California (Fig. 1). The region is within the burn perimeter of the Basin Complex Fire, ignited from a dry lightning storm in late June, 2008. The area features a Mediterranean-type climate and a rugged landscape dissected by steep slopes and drainage networks with elevations ranging from sea level to $1571 \mathrm{~m}$ within $5 \mathrm{~km}$ of the coast (Meentemeyer et al., 2008). Major forest types include mixed coniferous forests, composed primarily of ponderosa pine (Pinus ponderosa), sugar pine (Pinus lambertiana), Jeffrey pine (Pinus jeffreyi), coulter pine (Pinus coulteri), and Santa Lucia Fir (Abies bracteata), and mixed oak woodlands consisting of coast live oak (Quercus agrifolia), Shreve's oak (Quercus parvula var. shrevei), California bay laurel (Umbellularia californica), and Pacific madrone (Arbutus menziesii), giving way to riparian corridors of redwood/tanoak (Sequoia sempervirens/Notholithocarpus densiflorus) dominated forests at lower elevations (Davis et al., 2010).

\subsection{Field data}

A network of long-term SOD monitoring plots (500 $\mathrm{m}^{2}$ each) in Big Sur was established in 2006 and 2007 to understand the responses of forest communities (e.g., host mortality) to the invasion of SOD. Plots were distributed in a stratified-random manner among two dominant forest types (redwood and mixed-evergreen) in areas with and without the pathogen (Meentemeyer et al., 2008). A total of 42 burned plots known to contain SOD-infected trees at the time of plot establishment were visited in September and October 2008, immediately following the containment of the Basin Complex Fire. The fire severity at each $500 \mathrm{~m}^{2}$ plot was scored using the composite burn index (CBI), a scale ranging from 0.00 to 3.00 used to quantify the damage to multiple forest strata across the entire plot (Key and Benson, 2005; Metz et al., 2011). In this study, we used the CBI values of the dominant tree layer, because the understory strata were not well captured by remotely sensed data. The $\mathrm{CBI}$ values ranged from 0.38 to 3.00 ( mean $=1.31$, median $=1.25$ standard deviation $=0.67$ ). . Because these plots were established prior to fire occurrence for understanding the responses of forest communities (e.g., host mortality) to the invasion of SOD (Meentemeyer et al., 2008), we also had data on prefire disease progression. We categorized disease progression at each plot into three stages based on physical characteristics of dead hosts (Metz et al., 2013): (i) early-stage (many dead host trees retained dried foliage and fine twigs), (ii) middle-stage (some older mortality with host trees losing fine crown fuels and surface fuels beginning to accumulate), and (iii) late-stage (most host trees have been dead for several years and have been falling to the ground) (Fig. 2).

\subsection{MASTER imagery and data preprocessing}

The MASTER (MODIS/ASTER) airborne simulator images from 12 flight transects covering the area of the Basin Complex Fire were acquired on August 26, 2008, immediately following the fire for rapid assessment. Each image scene contains 50 bands covering visible-shortwave infrared (VNIR-SWIR: bands 1-25), mid infrared (MIR: bands 26-40), and thermal infrared (TIR: bands 41-50) spectral regions (Hook et al., 2001). With altitudes kept in a small range between 3076 and $3079 \mathrm{~m}$, the images had an average spatial resolution of $4 \mathrm{~m}$. All MASTER data were obtained as a Level 1B product standard that was radiometrically calibrated, geo-located, and encapsulated in hierarchical data format.

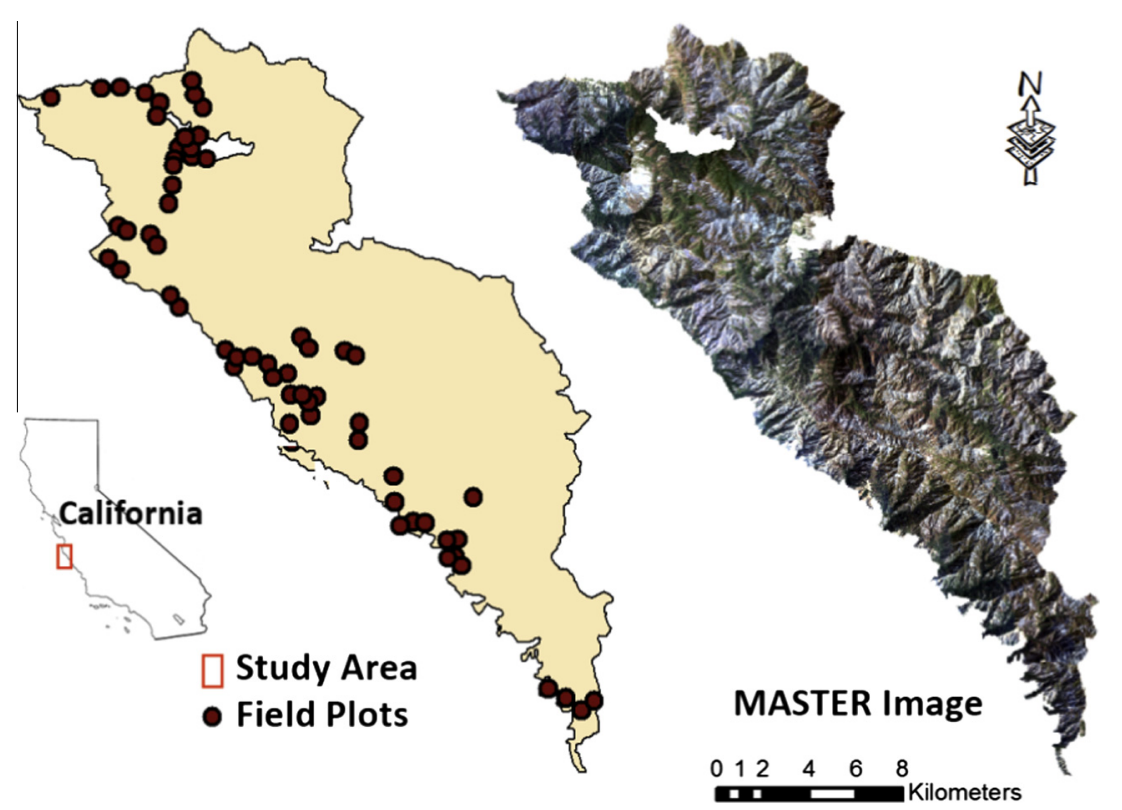

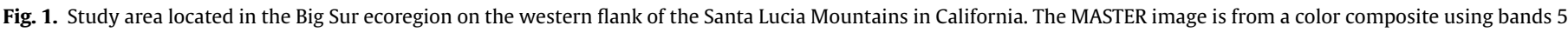
(red), 3 (green) and 1 (blue). (For interpretation of the references to color in this figure legend, the reader is referred to the web version of this article.) 
(a)

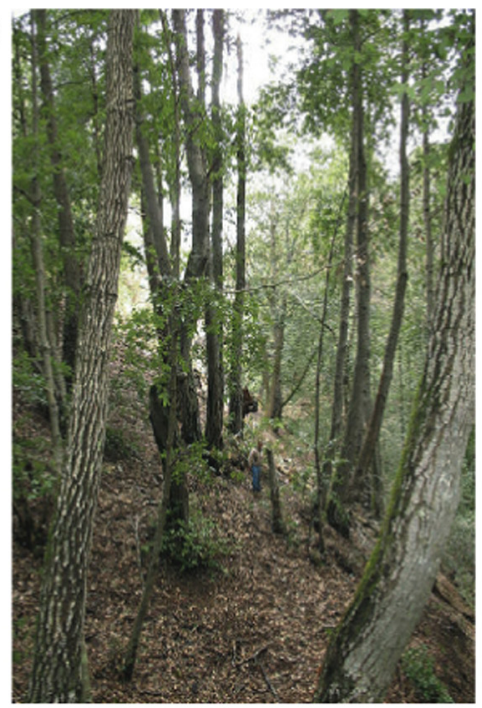

(c)

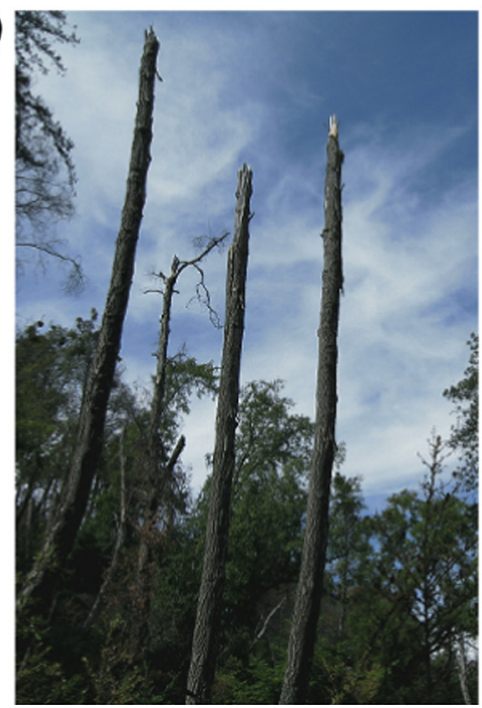

(b)

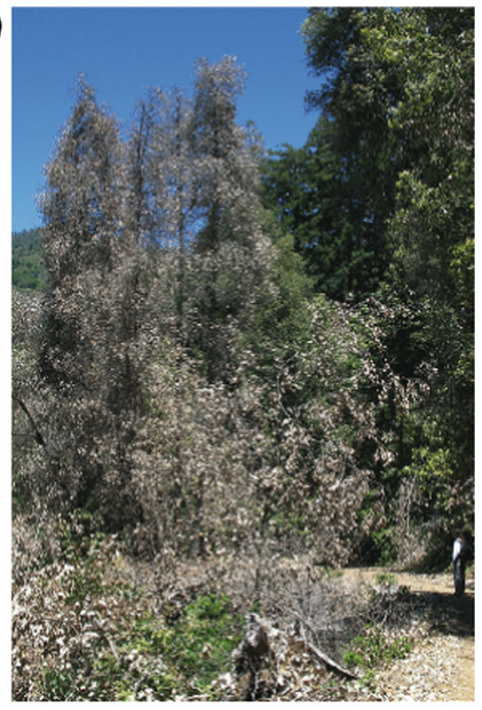

(d)

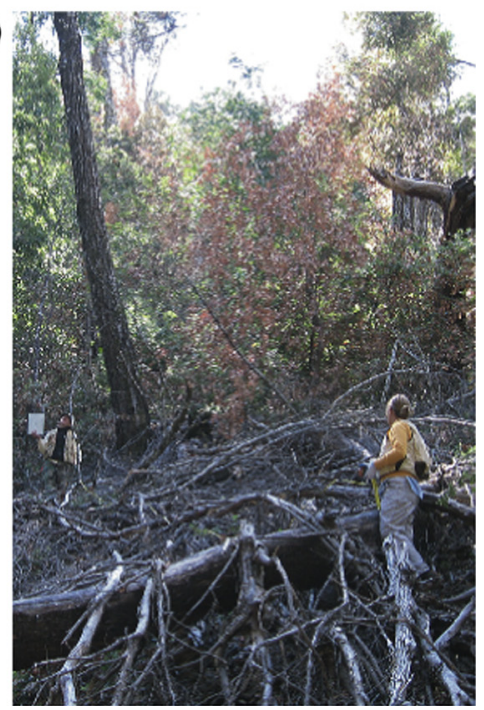

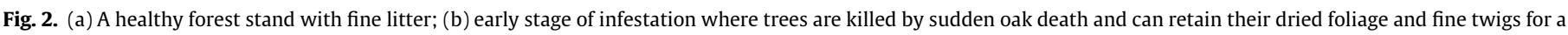

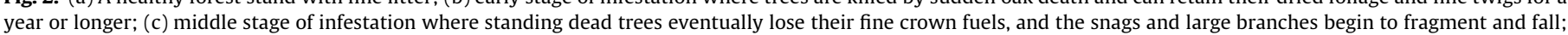
and (d) late stage of infestation where fallen trees and branches create large piles of ground fuels in areas (Metz et al., 2013).

The pre-processing of MASTER data includes four main steps: (i) minimizing the view-angle brightness gradient; (ii) image mosaicking; (iii) radiometric correction, and (iv) topographic correction. Specifically, (i) the sun and sensor geometry influences the data quality with each image transect being relatively bright on one side and dark on the other side. To minimize this view-angle brightness gradient, we fit a quadratic curve to each column to simulate the changes in brightness across view angles, and then applied a multiplicative compensation method to compensate each pixel following methods of Kennedy et al. (1997), who successfully removed the view-angle effect in AVIRIS hyperspectral imagery. (ii) The 12 transects were then mosaicked in sequence using the overlapped area from one image to balance the data range of its neighboring image. (iii) We used the dark object subtraction algorithm to derive surface radiance from the image mosaic in the VNIRSWIR region (Chavez, 1996). No atmospheric correction was applied to the MIR region, as it has been found to be insensitive to the presence of most aerosols (Kaufman and Rehmer, 1994; Harris et al., 2011). In the TIR region, surface emissivity was extracted by separating it from the surface temperature using the emissivity normalization technique developed by Kealy and Hook
(1993). (iv) Finally, a topographic correction was applied to normalize for different illumination conditions caused by topography using the C-correction method (Teillet et al., 1982) and a $30 \mathrm{~m}$ DEM derived from data collected by ASTER sensor as part of the global digital elevation model (GDEM) project (ASTER GDEM Validation Team, 2009).

\subsection{Spectral band reduction}

Using all 50 spectral bands from the MASTER image mosaic in the GEOBIA process would significantly increase the computation requirements during image segmentation and object-based feature extraction, as well as during the selection of the optimal subset from hundreds of object-based variables for burn severity assessment. To ease computational requirements, we used two statistical algorithms to reduce the number of input spectral bands prior to the object-based analysis: principal component analysis (PCA) and minimum noise fraction (MNF).

Both PCA and MNF are well-known spectral transformation methods in remote sensing. PCA (also known as Karhunen-Loéve analysis) converts the correlated spectral bands from the original 
image into a set of linearly uncorrelated components using an orthogonal transformation (Jolliffe, 2002). The proportion of variance explained by each component is calculated using eigenvalues, with the first component accounting for the single greatest proportion of the variance across all the original spectral bands. Each subsequent component accounts for the next largest proportion of the remaining variance (Holden and LeDrew, 1998). Fig. 3(a) shows the percentage of variance (calculated using eigenvalues) explained by the number of PCA components. The first component accounted for the maximum variance of $68.3 \%$. Cumulatively, the top 5 components accounted for $93.9 \%$ of the variance, while the top 10 components together explained $98.1 \%$ of the total variance. Similar to PCA, MNF seeks to derive new uncorrelated bands based upon two cascaded PCA transformations, but unlike PCA, MNF optimizes the signal-to-noise ratio to produce principal component images ordered by decreasing signal quality (Green et al., 1988). Fig. 3(b) represents the relationship between the calculated MNF components and variance explained by the number of MNF components. The top 5 and top 10 components accounted for $57.6 \%$ and $68.7 \%$ of the total variance, respectively. The components that contained low variance were primarily composed of noise. To increase computation efficiency and compare band reduction scenarios, we selected the top 5 and then top 10 components from the PCA and MNF transformed images, representing $10 \%$ and $20 \%$ of the total number of the original MASTER spectral bands. This resulted in five band reduction scenarios: no band reduction (i.e., the 50 original bands), 5 PCA components, 10 PCA components, 5 MNF components, and $10 \mathrm{MNF}$ components.

\subsection{Object-based burn severity modeling}

GEOBIA provides an appropriate solution to capture meaningful ground objects while reducing high spectral variability in highspatial resolution imagery (Chen et al., 2012). As a prerequisite of GEOBIA, image segmentation requires defining the size and shape of objects. In this study, eCognition Developer 8 (Trimble Navigation, Sunnyvale, California) was applied to segment the original MASTER 50-band image mosaic, as well as each transformed component image after band reduction (Section 2.4). A scale parameter (defining mean object size) of 30 was used to derive image objects at the small forest patch level aiming to capture high heterogeneity. The parameters of shape and compactness were set to the software default values of 0.1 (shape) and 0.8 (compactness). We also evaluated other parameter values and had similar segmentation results. The main reason is that in the natural forest environment canopy shadows are often interspersed with spectral responses of tree leaves across varying incident angles, introducing high spectral variation. All the segmentation parameters were initially derived under the no-band-reduction scenario and then applied to the other four scenarios to enable the examination of how band reduction affected image homogeneity and object characteristics. In particular, if the same set of segmentation parameters is used, images of different spectral variations could differ from each other in defining object size and shape. The size was calculated by recording the number of object boundary pixels, while the shape was calculated using the shape index (SI), which measures the complexity of an object's shape by comparing it to a standard shape (square) of the same size and alleviates the size dependency by using a perimeter $\left(p_{i}\right)$ and area $\left(a_{i}\right)$ for each image object $i$ (Forman and Godron, 1986):

$\mathrm{SI}=0.25 p_{i} / \sqrt{a_{i}}$

which equals 1 if the shape is a square. A non-compact object has a shape index value greater than 1 .

Three types of remote sensing variables were extracted from the segmentation-derived image objects, including band/component, internal texture, and neighborhood texture (Table 1). Specifically, (i) band/component was calculated by averaging spectral reflectance or PCA/MNF component values within each image object. (ii) Internal texture was derived by calculating the standard deviation within each image object. (iii) Neighborhood texture describes the relationship between neighboring objects and was calculated as the standard deviation of the averaged pixel values from the center object and its immediate neighbors (Chen et al., 2011). These three variables were calculated for each image band or component in each of the feature extraction scenarios resulting in a total number of $150,15,30,15$ and 30 variables for the five scenarios of no band reduction, 5 PCA components, 10 PCA components, 5 MNF components, and 10 MNF components, respectively. Obviously, if no band reduction was performed, the number of variables used in burn severity modeling would substantially increase (e.g., 150 versus 15). The plots where the dependent variable of field-measured CBI was collected were overlaid onto the image objects and the object-based dependent variable values were extracted from the spatially corresponding objects. Here, we followed Castilla and Hay (2008) by assuming each image object to be homogenous and have great potential to represent meaningful geographic objects. We also recognized the spatial variability of field data and image objects; however, it remained challenging to take the variability into consideration when assigning plot values to image objects. In this study, all the variables were extracted using custom code written in interactive data language (IDL; ITT Exelis, McLean, Virginia, USA).

In this research, stepwise multiple regression models were developed for burn severity assessment. For each scenario of the variable reduction (Section 2.4), three models were developed

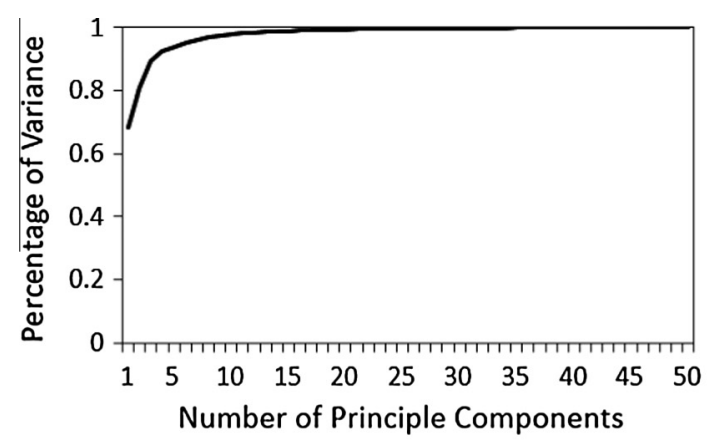

(a)

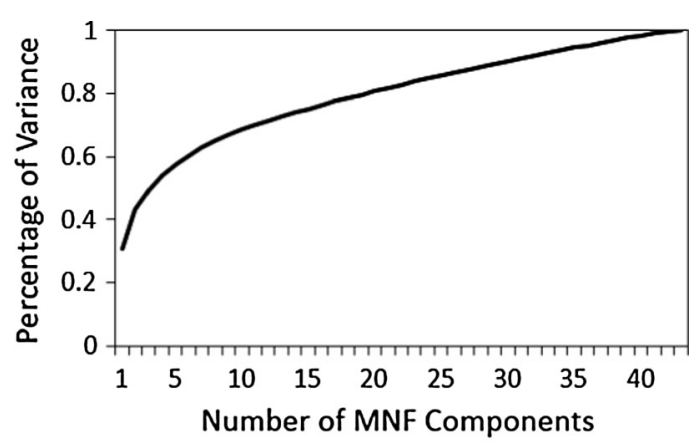

(b)

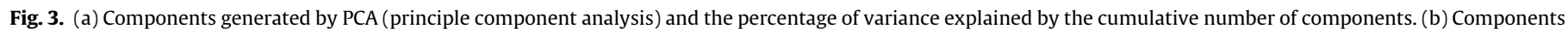
generated by MNF (minimum noise fraction) and the percentage of variance explained by the cumulative number of MNF components. 
Table 1

Three types of variables derived from remote sensing imagery.

\begin{tabular}{|c|c|c|}
\hline Variable type & Variable name & Description \\
\hline Band/component & $\mathrm{BD} i$ & Average of spectral reflectance or component values for the $i$ th ${ }^{*}$ band/component within image objects \\
\hline Internal texture & TXITi & Internal standard deviation for the ith band within image objects \\
\hline Neighborhood texture & GEOTEXi & Neighboring standard deviation for the $i$ th band within neighboring image objects \\
\hline
\end{tabular}

$i$ represents band/component number.

corresponding to three stages of disease progression, resulting in a total number of 15 regression models. To reduce multicollinearity, the Pearson's linear correlation coefficients were calculated for all the remote sensing predictor variables prior to regression analysis. If the coefficient between two variables was higher than 0.7 (Dormann et al., 2012), only the variable that had higher correlation with field-measured CBI was retained. Based on this rule, redundant independent variables were discarded before applying the forward stepwise regression with all models developed at a 0.05 significance level. During modeling, variance inflation factor (VIF) was also calculated to detect the influence of multicollinearity among the predictor variables. All predictor variables with a VIF smaller than 5 were retained in our analyses (Neter et al., 1996). Field plots were split into three groups based on the three stages of disease progression, resulting in each group having between 11 and 20 measurements of CBI. Thus, a leave-one-out cross-validation technique (Davis, 1987) was chosen to calculate root mean square error (RMSE) of each burn severity model. Model development and validation were performed using IDL code (ITT Exelis, McLean, Virginia, USA).

\section{Results and discussion}

\subsection{Comparison of image objects}

PCA and MNF transformations are two types of band reduction algorithms, which generated different new components and image objects (Fig. 4). Specifically, Fig. 4 represents a comparison of image objects (with white polygon boundaries) in a sample study site for the five band reduction scenarios (a) no band reduction (i.e., 50 bands), (b) 5 PCA components, (c) 10 PCA components, (d) 5 MNF components, and (e) 10 MNF components. The backdrop of (a) is a true color composite using MASTER bands 5, 3, and 1, where light tones represent ash, brown colors indicate moderate burns in forest stands, and a small portion of green trees indicate low levels of fire damage. The backdrops of (b) and (c) are the color composites using the first three PCA components, while the backdrops of (d) and (e) are the color composites using the first three MNF components. Compared to the MNF-based image objects (hereafter MNF objects), the PCA-based image objects (hereafter $P C A$ objects) were more similar to the objects generated using the original 50 spectral bands (hereafter hyperspectral objects) (Table 2 and Fig. 4). Because the same set of segmentation parameters (i.e., scale, shape and compactness) were employed to generate image objects from the original spectral bands for the PCA/MNF components, the resulting objects with similar characteristics (e.g., size and shape) could indicate similar variance within the pre-segmentation imagery. This is confirmed by the fact that the first 5 or 10 PCA components in (b) and (c) explained more variance than the first 5 or $10 \mathrm{MNF}$ components in (d) and (e) $(93.9 \%$ or $98.1 \%$ versus $57.6 \%$ or $68.7 \%$ ). The PCA objects were on average $35 \%$ ( 0.28 versus $0.79 \mathrm{ha}$ ) and $68 \%$ ( 0.54 versus $0.79 \mathrm{ha}$ ) of the size of hyperspectral objects, while the MNF objects were 5.4 (4.27 versus 0.79 ha) and 8.3 times (6.54 versus $0.79 \mathrm{ha}$ ) larger than the hyperspectral objects (Table 2). The comparison of object shape provided similar results, where the PCA and hyperspectral objects were comparable ( 1.90 or 2.05 versus 2.12 ha) and MNF objects were much less complex (1.62 or 1.50 versus 2.12 ha; Table 2, Fig. 4). For example, using the same set of segmentation parameters the severely burned forest stands [yellow color in (d) and (e)] were composed of less than 10 MNF objects, but were made up of more than 40 spectral or PCA objects.

Compared to the no-band-reduction scenario, the PCA transformation led to mild over-segmentation, while the MNF algorithm resulted in notable under-segmentation. Although both algorithms rely on a similar principle of data transformation by orthogonalizing the original feature space, a unique step in MNF is the calculation of a noise covariance matrix to decorrelate noise content rather than just maximizing the captured variance as PCA does (Green et al., 1988). In addition to reducing spectral noise, MNF also dramatically condensed the image spectral variation. In a forest environment, such variation is typically introduced by multiple tree structures, snags, gaps, and shadows. In this study, the variation was boosted by the combination of disease and fire caused tree stress and dieback, ash accumulations, and changes in soil properties. Compared to MNF, PCA had a marginal impact on reducing the spectral variation of the MASTER image mosaic.

\subsection{Comparison of burn severity models}

The adjusted determination of coefficients $\left(R^{2}\right)$ and RMSEs of the burn severity models (for the five band reduction scenarios and three stages of disease progression), and all of the statistically

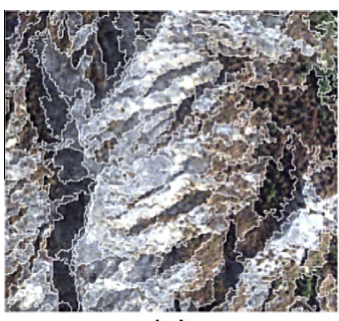

(a)

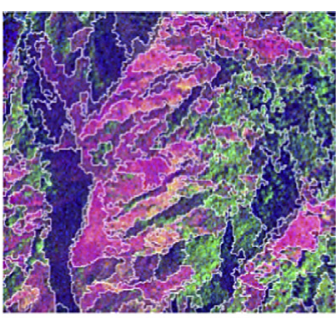

(b)

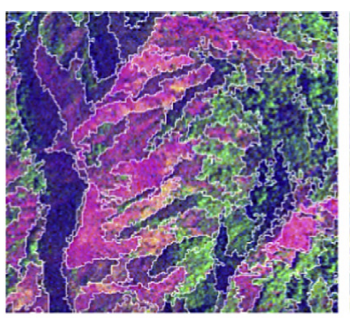

(c)

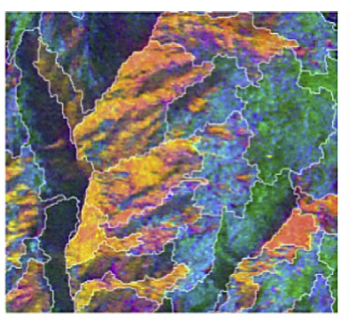

(d)

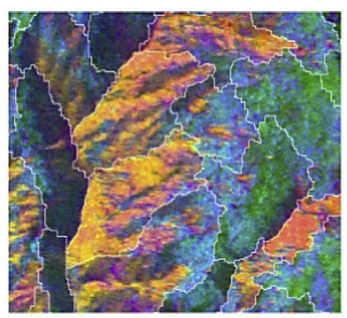

(e) ${ }_{0}^{\longrightarrow} \quad 100 \mathrm{~m}$

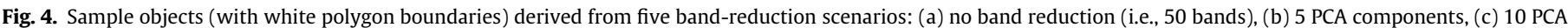

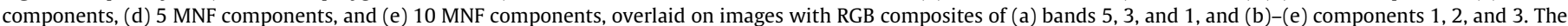

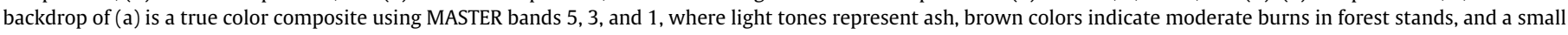

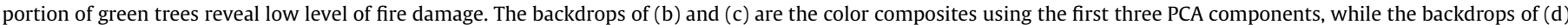

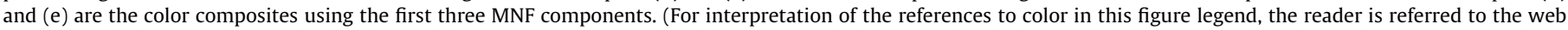
version of this article.) 
Table 2

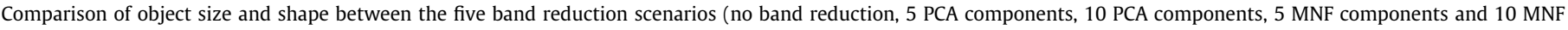
components).

\begin{tabular}{|c|c|c|c|c|c|c|c|c|}
\hline \multirow[t]{2}{*}{ Scenario } & \multicolumn{4}{|c|}{ Object size (ha) } & \multicolumn{4}{|c|}{ Object shape } \\
\hline & Minimum & Maximum & Mean & Standard deviation & Minimum & Maximum & Mean & Standard deviation \\
\hline No band reduction & 0.01 & 9.43 & 0.79 & 0.64 & 0.35 & 5.00 & 2.12 & 0.57 \\
\hline 5 PCA components & 0.01 & 3.72 & 0.28 & 0.25 & 0.35 & 4.96 & 1.90 & 0.60 \\
\hline 10 PCA components & 0.01 & 6.51 & 0.54 & 0.44 & 0.35 & 5.01 & 2.05 & 0.58 \\
\hline 5 MNF components & 0.10 & 63.30 & 4.27 & 3.11 & 1.01 & 5.19 & 1.62 & 0.32 \\
\hline 10 MNF components & 0.02 & 75.58 & 6.54 & 4.69 & 1.02 & 3.95 & 1.50 & 0.29 \\
\hline
\end{tabular}

significant remote sensing variables used in these models are presented in Table 3. Under the no-band-reduction scenario, the models developed for the three stages had relatively similar results $\left(R^{2}=0.60,0.55\right.$ and 0.64 , and RMSE $=0.31,0.42$ and 0.47$)$, while the application of band reduction resulted in much greater variation between models across the three stages. Table 3 shows that the $R^{2}$ values of the early stage models ranged from 0.35 to 0.86 (standard deviation of 0.19 ); while $R^{2}$ values ranged from 0.57 to 0.92 (standard deviation of 0.16 ) and $0.61-0.76$ (standard deviation of 0.07 ) for the middle and late stage models, respectively. In all cases, the application of 10 components always improved the burn severity modeling results with higher $R^{2}$ values and lower RMSEs than the use of 5 components. As presented in Table 3, such improvements ranged from $4 \%$ to $22 \%$ using PCA, and 5-31\% using MNF. However, the magnitude of improvements was stage-dependent with more discussions about the model performance at individual stages provided in the succeeding paragraphs. When comparing the two band reduction algorithms, Table 3 shows that the PCA-based models outperformed the MNF-based models (using the same number of components) in four (out of the six) cases. And in one of the two remaining cases, they had similar performance $\left(R^{2}=0.59\right.$ versus 0.61$)$. Although MNF had high capacity to reduce both the spectral noise and spectral variation in the MASTER image mosaic as discussed in Section 3.1, the fact that PCA-based models delivered superior performance suggests that some spectral variation contributing to the burn severity modeling in diseaseimpacted forests may have been removed through MNF transformations together with the real noise.

At the early stage of disease progression, the dead trees may retain dry foliage and fine twigs, giving them a "freeze-dried" appearance (Kelly and Meentemeyer, 2002). As a result, there should be a noticeable decrease in the near infrared spectral reflectance and a rise in the shortwave infrared reflectance, similar to the reflectance produced by fire-induced ash (Roy and Landmann, 2005). This might explain the phenomenon where the early stage model using all the 50 bands overestimated the impact of low severity of burns (Fig. 5). In terms of applying PCA or MNF components in modeling low severity burns, Table 3 shows that the new models almost always have lower $R^{2}$ values and higher RMSEs (except using the MNF 10 components) than those applying the original spectral bands. As illustrated in Fig. 5, the reduced model performance may be due to an overestimation of the impact of low-severity fires and an underestimation of the impact of medium-severity fires. In a forest environment, tree crowns often dominate the contribution of forest reflectance, although the background soil/vegetation and tree shadows may also add substantial variation to remotely sensed imagery, especially when the data has both high-spatial and high-spectral resolutions. Our results suggest that often the variation removed by either the PCA or MNF algorithm was vital to burn severity modeling at the early stage of disease progression where tree mortality led to a "freeze-dried" appearance. After transformations, the spectral reflectance from dried foliage and fine twigs was possibly enhanced, resulting in a higher degree of overestimation of lowseverity burns. An exception occurred when the 10 MNF components with a mean object size of 6.54 ha were used in modeling.

The loss of tree crowns in the middle and late stages of disease progression enabled better signal penetration and a lower spectral variation in the MASTER image mosaic. Especially for the middle stage, Table 3 shows that all models based on the band reduction had improved $R^{2}$ values ranging from $2 \%$ to $37 \%$, compared to the models using the original spectral bands. Even when only 5 PCA

Table 3

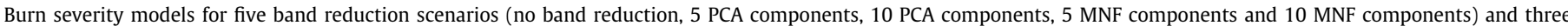
stages of disease progression (early, middle and late).

\begin{tabular}{|c|c|c|c|c|}
\hline Scenario & Stage & Adjusted $R$-squared value & Significant independent variable & RMSE \\
\hline No band reduction & $\begin{array}{l}\text { Early } \\
\text { Middle } \\
\text { Late }\end{array}$ & $\begin{array}{l}0.60 \\
0.55 \\
0.64\end{array}$ & $\begin{array}{l}\mathrm{BD}_{16}{ }^{*}, \mathrm{BD}_{50}{ }^{*}, \mathrm{GEOTEX}_{13}{ }^{* *} \\
\mathrm{TXIT}_{7}{ }^{*}, \mathrm{TXIT}_{50}{ }^{*} \\
\text { TXIT }_{19}{ }^{*}\end{array}$ & $\begin{array}{l}0.31 \\
0.42 \\
0.47\end{array}$ \\
\hline 5 PCA components & $\begin{array}{l}\text { Early } \\
\text { Middle } \\
\text { Late }\end{array}$ & $\begin{array}{l}0.46 \\
0.66 \\
0.59\end{array}$ & $\begin{array}{l}\mathrm{BD}_{5}^{*} \\
\mathrm{BD}_{2}^{*}, \mathrm{BD}_{5}^{* *}, \mathrm{TXIT}_{4}^{*} \\
\mathrm{TXIT}_{1}^{*}\end{array}$ & $\begin{array}{l}0.44 \\
0.37 \\
0.53\end{array}$ \\
\hline 10 PCA components & $\begin{array}{l}\text { Early } \\
\text { Middle } \\
\text { Late }\end{array}$ & $\begin{array}{l}0.50 \\
0.92 \\
0.76\end{array}$ & $\begin{array}{l}\mathrm{BD}_{2}{ }^{*}, \mathrm{GEOTEX}_{6}{ }^{*} \\
\mathrm{BD}_{2}{ }^{*}, \mathrm{TXIT}_{4}{ }^{*}, \mathrm{TXIT}_{5}{ }^{* *}, \mathrm{GEOTEX}_{2}{ }^{*} \\
\mathrm{BD}_{1}{ }^{*}, \mathrm{BD}_{4}{ }^{*}, \mathrm{GEOTEX}_{4}{ }^{*}\end{array}$ & $\begin{array}{l}0.40 \\
0.23 \\
0.41\end{array}$ \\
\hline 5 MNF components & $\begin{array}{l}\text { Early } \\
\text { Middle } \\
\text { Late }\end{array}$ & $\begin{array}{l}0.35 \\
0.57 \\
0.61\end{array}$ & $\begin{array}{l}\mathrm{TXIT}_{2}^{* *} \\
\mathrm{BD}_{3}^{*}, \mathrm{BD}_{5}^{*}, \mathrm{TXIT}_{1}^{* *} \\
\mathrm{TXIT}_{2}^{* *}, \mathrm{GEOTEX}_{2}^{* *}\end{array}$ & $\begin{array}{l}0.47 \\
0.43 \\
0.52\end{array}$ \\
\hline 10 MNF components & $\begin{array}{l}\text { Early } \\
\text { Middle } \\
\text { Late }\end{array}$ & $\begin{array}{l}0.86 \\
0.79 \\
0.66\end{array}$ & $\begin{array}{l}\operatorname{TXIT}_{7}^{*}, \text { GEOTEX }_{4}^{* *}, \text { GEOTEX }_{6}^{*} \\
\mathrm{BD}_{5}^{*}, \mathrm{TXIT}_{7}^{*} \\
\mathrm{BD}_{5}^{* * *}, \mathrm{BD}_{10}{ }^{* *}, \mathrm{GEOTEX}_{7}^{* *}\end{array}$ & $\begin{array}{l}0.24 \\
0.33 \\
0.46\end{array}$ \\
\hline
\end{tabular}



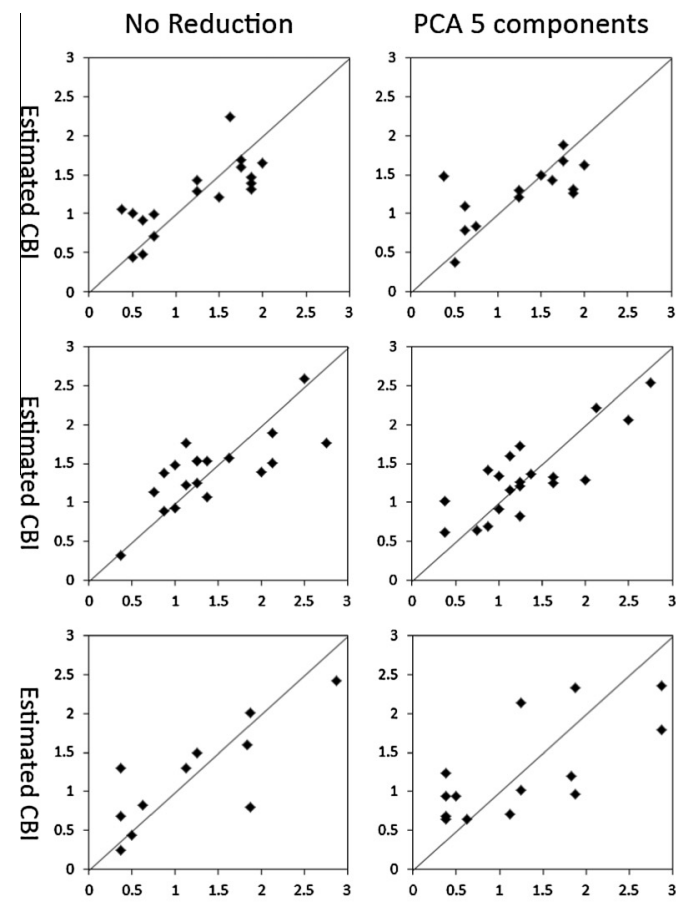

Field-measured $\mathrm{CB}$

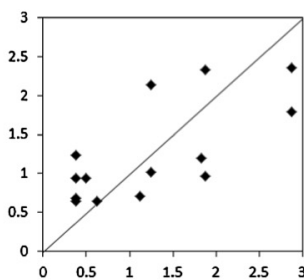

Field-measured CBI
PCA 10 components
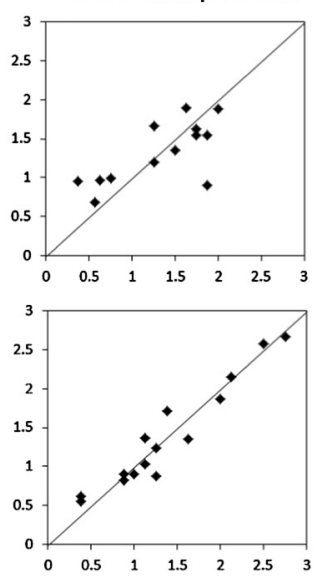

MNF 5 components
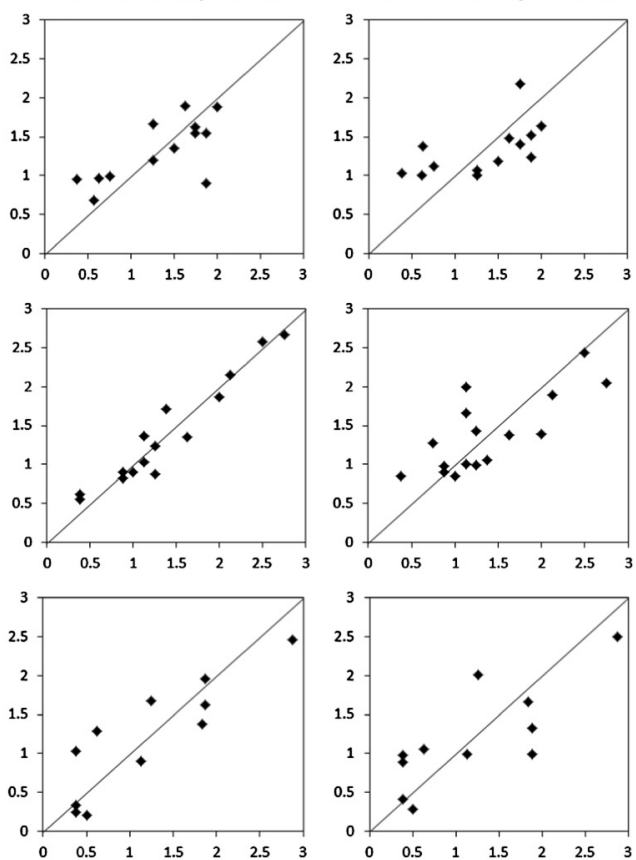

Field-measured $\mathrm{CBI}$

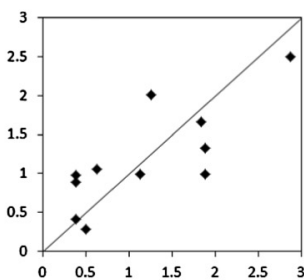

Field-measured CB
MNF 10 components
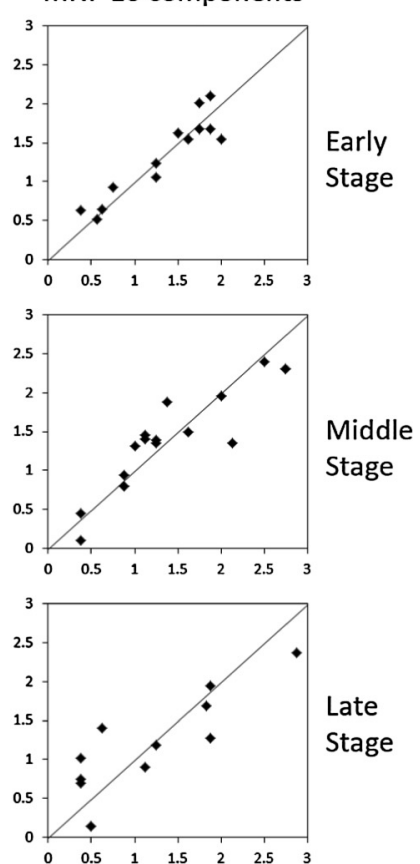

Field-measured $\mathrm{CBI}$

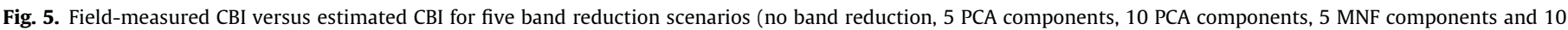
MNF components) and three stages of disease progression (early, middle and late).

components (accounting for $10 \%$ of the number of original image bands) were used in the regression the model performance improved, with $R^{2}$ values increasing from 0.55 to 0.66 . For the late stage, Table 3 shows that the two models using 5 PCA and 5 MNF components slightly underperformed the burn severity model without the application of band reduction by $5 \%$ and $3 \%$. When using 10 components, the model performance improved marginally by $7 \%$ and $2 \%$. Since the variation of $R^{2}$ values among these models was relatively small ( $7 \%$ of standard deviation), both band reduction algorithms were considered to be able to retain the accuracy of burn severity modeling in forest stands at the late stage of disease progression. Compared to the middle-stage, the late-stage forest stands were covered by large piles of fallen trees and branches, resulting in relatively higher variability in the MASTER imagery. This may introduce uncertainties in the late-stage modeling results after applying band reduction. Compared to the earlystage condition, both PCA and MNF provided a better balance of computation efficiency and accuracy of burn severity models for the middle- and late-stage conditions.

\section{Conclusion}

Increasingly, forest ecosystems are experiencing a variety of complex and interacting disturbances. Large fires are occurring more frequently and burning forest stands where invasive diseases have already caused high tree mortality. This study investigated the possibility of applying MASTER airborne imagery with both highspatial ( $4 \mathrm{~m}$ ) and high-spectral (50 bands) resolutions to assess post-fire burn severity in forests affected by three different stages of pre-fire mortality (i.e., early - trees retaining dried foliage and fine twigs, middle - trees losing fine crown fuels, late - trees falling down) due to SOD. While GEOBIA is gradually becoming a standard tool for analyzing high-spatial resolution imagery, high-spectral resolution imagery with dozens to hundreds of bands can dramatically reduce computation efficiency and poses challenges to the object-based variable selection for accurate burn severity modeling. This study further evaluated the impacts of two widely used band reduction algorithms PCA and MNF on the delineation of image objects and the resulting accuracy of burn severity modeling. If no band reduction was applied, the models developed for the three stages of disease progression had relatively similar performance, suggesting that the invasion of SOD did not have a major impact on the performance of burn severity modeling using unreduced images of high-spatial and high-spectral resolutions, but this is computationally intensive. However, the application of PCA and MNF introduced substantial variability among the segmentation and modeling results across the three stages. Compared to the image objects generated using all the 50 spectral bands, our results show that the PCA components led to mild over-segmentation (i.e., smaller mean object sizes) and the shape of objects was marginally affected, while the MNF components resulted in notable under-segmentation (i.e., larger mean object sizes) and the shape of image objects exhibited reduced complexity by $24 \%$ and $29 \%$ using the top 5 and top 10 MNF components, respectively. Compared to PCA, MNF dramatically reduced image spectral variation, generating larger image objects with less complexity of object shapes. However, PCA-based models outperformed the MNF-based models in most cases, suggesting that MNF may have removed some variation that was vital for distinguishing between spectral reflectance from diseased trees and fire-induced ash or charred remains. Comparison of the early-stage burn severity models showed that both band reduction algorithms were typically unable to improve or retain the model performance over no-band-reduction, except for the model using $10 \mathrm{MNF}$ components. Compared to the no-bandreduction scenario, band reduction led to a higher level of overestimation of low degrees of burns and underestimation of medium degrees of burns, probably due to the fact that both PCA and MNF enhanced the reflectance from dried tree crowns similar to the way fire-induced ash change the reflectance. For the middle and late stages, trees losing crowns allowed for improved signal penetration and a lower spectral variation in the MASTER image mosaic. 
Consequently, the two band reduction algorithms evaluated in this research (using 10 PCA/MNF components as input) showed promising results of balancing computation efficiency and the performance burn severity modeling in the forests stands subject to the middle and late stages of SOD progression. Finally, we note that the conclusions made from the burn severity models using PCA and MNF are scene-dependent. If the landscape is covered by forests with different structures and/or subject to distinct disease impacts, the post-fire spectral variation at various infestation stages may also differ from that observed in this study. Compared to the model involving PCA and MNF, the no-band-reduction models may have higher transferability across varying forest landscapes, but remain computationally expensive.

\section{Acknowledgements}

This research was supported by the National Science Foundation (EF-0622770) as part of the joint NSF-NIH Ecology and Evolution of Infectious Disease program. The authors also gratefully acknowledge financial support from the USDA Forest Service Pacific Southwest Research Station, the Gordon \& Betty Moore Foundation, and support to Dr. Gang Chen from North Carolina Space Grant, the University of North Carolina at Charlotte Faculty Research Grant, and College of Liberal Arts and Sciences Seed Grant. We thank numerous contributors who provided vital field and laboratory support, including K. Aram, M. Beh, A. Brauer, M. Chan, R. Cobb, C, DeLong, W. Dillon, K. Frangioso, A. Hohl, H. Mehl, A. Oguchi, E. Paddock, K. Pietrzak, M. Vaclavikova, J. Vieregge, L. Waks and A. Wickland. Three anonymous reviewers provided comments that significantly improved the manuscript.

\section{References}

Asner, G.P., 2013. Geography of forest disturbance. Proc. Natl. Acad. Sci. 110, 37113712.

ASTER GDEM Validation Team, 2009. ASTER Global DEM Validation: Summary Report, June 2009. <https://lpdaac.usgs.gov/sites/default/files/public/aster/ docs/ASTER_GDEM_Validation_Summary_Report.pdf> (accessed 25.07.14).

Aukema, J.E., McCullough, D.G., Von Holle, B., Liebhold, A.M., Britton, K., Frankel, S.J., 2010. Historical accumulation of nonindigenous forest pests in the continental United States. Bioscience 60, 886-897.

Bergot, M., Cloppet, E., Pérarnaud, V., Déqué, M., Marcais, B., Desprez-Loustau, M.-L., 2004. Simulation of potential range expansion of oak disease caused by Phytophthora cinnamomi under climate change. Glob. Change Biol. 10, 15521939.

Blaschke, T., Hay, G.J., Kelly, M., Lang, S., et al., 2014. Geographic object-based image analysis - towards a new paradigm. ISPRS J. Photogramm. Remote Sens. 87, $180-191$.

Boyd, I.L., Freer-Smith, P.H., Gilligan, C.A., Godfray, H.C.J., 2013. The consequence of tree pests and diseases for ecosystem services. Science 342, 1235773.

Castilla, G., Hay, G.J., 2008. Image objects and geographic objects. In: Blaschke, T., Lang, S., Hay, G.J. (Eds.), Object-Based Image Analysis. Springer, Berlin, Heidelberg, pp. 91-110.

Chavez, P., 1996. Image-based atmospheric corrections - revisited and improved. Photogramm. Eng. Remote Sens. 62, 1025-1036.

Chen, G., Hay, G.J., Castilla, G., St-Onge, B., 2011. A multiscale geographic objectbased image analysis to estimate lidar-measured forest canopy height using Quickbird imagery. Int. J. Geogr. Inform. Sci. 25, 37-41.

Chen, G., Hay, G.J., St-Onge, B., 2012. A GEOBIA framework to estimate forest parameters from lidar transects, Quickbird imagery and machine learning: a case study in Quebec, Canada. Int. J. Appl. Earth Obs. Geoinf. 15, 28-37.

Davis, B.M., 1987. Uses and abuses of cross-validation in geostatistics. Math. Geol. $19,241-248$.

Davis, F.W., Borchert, M.I., Flint, A., Meentemeyer, R.K., Rizzo, D.M., 2010. Preimpact forest composition and ongoing tree mortality associated with sudden oak death disease in the Big Sur region, California. For. Ecol. Manage. 259, 23422354.

Dormann, C.F., Elith, J., Bacher, S., Buchmann, C., Carl, G., Carre, G., Garcia Marquez, J.R., Gruber, B., Lafoourcade, B., Leitao, P.J., Münkemüller, T., Mcclean, C., Osborne, P.E., Reineking, B., Schröder, B., Skidmore, A.K., Zurell, D., Lautenbach, S., 2012. Collinearity: a review of methods to deal with it and a simulation study evaluating their performance. Ecography 35, 1-20.

Forman, R.T.T., Godron, M., 1986. Landscape Ecology. John Wiley \& Sons, New York, p. 619.
Green, A., Berman, M., Switzer, P., Craig, M.D., 1988. A transformation for ordering multispectral data in terms of image quality with implications for noise removal. IEEE Trans. Geosci. Remote Sens. 26, 65-74.

Guyot, G., Guyon, D., Riom, J., 1989. Factors affecting the spectral response of forest canopies: a review. Geocarto Int. 4, 3-18.

Hall, D.K., Ormsby, J.P., Johnson, L., Brown, J., 1980. Landsat digital analysis of the initial recovery of burned tundra at Kokolik River, Alaska. Remote Sens. Environ. $10,263-272$.

Harris, S., Veraverbeke, S., Hook, S., 2011. Evaluating spectral indices for assessing fire severity in chaparral ecosystems (Southern California) Using MODIS/ASTER (MASTER) airborne simulator data. Remote Sens. 3, 2403-2419.

Harvey, B.J., Donato, D.C., Romme, W.H., Turner, M.G., 2013. Influence of recent bark beetle outbreak on fire severity and postfire tree regeneration in montane Douglas-fir forests. Ecology 94, 2475-2486.

Hay, G.J., Castilla, G., 2008. Geographic Object-Based Image Analysis (GEOBIA). In: Blaschke, T., Lang, S., Hay, G.J. (Eds.), Object-Based Image Analysis - Spatial Concepts for Knowledge-Driven Remote Sensing Applications. Springer-Verlag, Berlin, pp. 77-92.

Hay, G.J., Niemann, K.O., McLean, G.F., 1996. An object-specific image-texture analysis of H-resolution forest imagery. Remote Sens. Environ. 55, 108-122.

Holden, H., LeDrew, E., 1998. Spectral discrimination of healthy and non-healthy corals based on cluster analysis, principal component analysis, and derivative spectroscopy. Remote Sens. Environ. 65, 217-224.

Hook, S.J., Myers, J.J., Thome, K.J., Fitzgerald, M., Kahle, A.B., 2001. The MODIS/ASTER airborne simulator (MASTER) - a new instrument for earth science studies. Remote Sens. Environ. 76, 93-102.

Hudak, A.T., Brockett, B.H., 2004. Mapping fire scars in a southern African savanna using Landsat imagery. Int. J. Remote Sens. 25, 3231-3243.

Jakubauskas, M.E., Lulla, K.P., Mausel, P.W., 1990. Assessment of vegetation changed in a fire altered forest landscape. Photogramm. Eng. Remote Sens. 56, 371-377.

Jenkins, M.J., Hebertson, E., Page, W., Jorgensen, C.A., 2008. Bark beetles, fuels, fires and implications for forest management in the Intermountain West. For. Ecol. Manage. 254, 16-34.

Jolliffe, I.T., 2002. Principal Component Analysis. Springer-Verlag, New York, p. 489.

Kaufman, Y., Rehmer, L., 1994. Detection of forests using mid-IR reflectance: an application for aerosol studies. IEEE Trans. Geosci. Remote Sens. 32, 672-683.

Kealy, P.S., Hook, S.J., 1993. Separating temperature and emissivity in thermal infrared multispectral scanner data: implications for recovering land surface temperatures. IEEE Trans. Geosci. Remote Sens. 31, 1155-1164.

Kelly, M., Meentemeyer, R.K., 2002. Landscape dynamics of the spread of sudden oak death. Photogramm. Eng. Remote Sens. 68, 1001-1009.

Kelly, M., Liu, D., McPherson, B., Wood, D., Standiford, R., 2008. Spatial pattern dynamics of oak mortality and associated disease symptoms in a California hardwood forest affected by sudden oak death. J. Forest Res. 13, 312-319.

Kennedy, R.E., Cohen, W.B., Takao, G., 1997. Empirical methods to compensate for a view-angle-dependent brightness gradient in AVIRIS imagery. Remote Sens. Environ. 62, 277-291.

Key, C., Benson, N., 2005. Landscape assessment: ground measure of severity, the composite burn index, and remote sensing of severity, the normalized burn index. In: Lutes, D., Keane, R., Caratti, J., Key, C., Benson, N., Sutherland, S., Gangi, L. (Eds.), FIREMON: Fire Effects Monitoring and Inventory System, Rocky Mountains Research Station, USDA Forest Service: Fort Collins, CO, USA, pp. 151.

Kurz, W.A., Dymond, C.C., Stinson, G., Rampley, G.J., Neilson, E.T., Carroll, A.L., Ebata, T., Safranyik, L., 2008. Mountain pine beetle and forest carbon feedback to climate change. Nature 452, 987-990.

Lentile, L.B., Holden, Z.A., Smith, A.M.S., Falkowski, M.J., Hudak, A.T., Morgan, P. Lewis, A.A., Gessler, P.E., Benson, N.C., 2006. Remote sensing techniques to assess active fire characteristics and post-fire effects. Int. J. Wildland Fire 15 319-345.

Meentemeyer, R.K., Rank, N.E., Shoemaker, D., Oneal, C., Wickland, A.C., Frangioso, K.M., Rizzo, D.M., 2008. Impacts of sudden oak death on tree mortality in the Big Sur ecoregion of California. Biol. Invasions 10, 1243-1255.

Meentemeyer, R.K., Haas, S.E., Vaclavik, T., 2012. Landscape epidemiology of emerging infectious diseases in natural and human-altered ecosystems. Annu. Rev. Phytopathol. 50, 379-402.

Metz, M.R., Frangioso, K.M. Meentemeyer, R.K., Rizzo, D.M., 2011. Interacting disturbances: wildfire severity affected by stage of forest disease invasion. Ecol. Appl. 21, 313-320.

Metz, M.R., Varner, J.M., Frangioso, K.M., Meentemeyer, R.K., Rizzo, D.M., 2013. Unexpected redwood mortality from synergies between wildfire and an emerging infectious disease. Ecology 94, 2152-2159.

Milne, A.K., 1986. The use of remote sensing in mapping and monitoring vegetational change associated with bushfire events in Eastern Australia. Geocarto Int. 1, 25-32.

Mitri, G.H., Gitas, I.Z., 2008. Mapping the severity of fire using object-based classification of IKONOS imagery. Int. J. Wildland Fire 17, 431-442.

Neter, J., Kutner, M.H., Nachtsheim, C.J., Wasserman, W., 1996. Applied Linear Regression Models. Burr Ridge, Irwin, Illinois, p. 720.

Olsson, P.-O., Jönsson, A.M., Eklundh, L., 2012. A new invasive insect in Sweden Physokermes inopinatus: tracing forest damage with satellite based remote sensing. For. Ecol. Manage. 285, 29-37.

Rizzo, D.M., Garbelotto, M., Hansen, E.M., 2005. Phytophthora ramorum: integrative research and management of an emerging pathogen in California and Oregon forests. Annu. Rev. Phytopathol. 43, 309-335. 
Roy, D.P., Landmann, T., 2005. Characterizing the surface heterogeneity of fire effects using multitemporal reflectance wavelength data. Int. J. Remote Sens. 26, 4197-4218.

Teillet, P.M., Guindon, B., Goodenough, D.G., 1982. On the slope-aspect correction of multispectral scanner data. Can. J. Remote Sens. 8, 84-106.

Thenkabail, P.S., Lyon, J.G., Huete, A., 2012. Hyperspectral Remote Sensing of Vegetation. CRC Press, Boca Raton, FL, p. 781.

Turner, M.G., Baker, W.L., Peterson, C.J., Peet, R.K., 1998. Factors influencing succession: lessons from large, infrequent natural disturbances. Ecosystems 1, 511-523.

U.S. Forest Service, 2014. Four Threats to the Health of the Nation's Forests and Grasslands. <http://www.fs.fed.us/projects/four-threats> (accessed 25.07.14).
USDA Forest Service, 2008. Executive Summary: Basin Complex Fire/Indians Fire BAER Initial Assessment, p. 16.

Veraverbeke, S., Hook, S.J., Harris, S., 2012. Synergy of VSWIR (0.4-2.5 $\mu \mathrm{m})$ and MTIR (3.5-12.5 $\mu \mathrm{m}$ ) data for post-fire assessments. Remote Sens. Environ. 124 771-779.

White, J.D., Ryan, K.C., Key, C.C., Running, S.W., 1996. Remote sensing of forest fire severity and vegetation recovery. Int. J. Wildland Fire 6, 125-136.

Wulder, M.A., Dymond, C.C., White, J.C., Leckie, D.G., Carroll, A.L., 2006. Surveying mountain pine beetle damage of forests: a review of remote sensing opportunities. For. Ecol. Manage. 221, 27-41. 